Brian Knight MD FRCPC

\title{
Management of the chronic-pain patient in an acute-pain service
}

\section{Case 1}

Ben presents for a lumbar discectomy. He complains of severe left leg pain. He takes eight to 12 Percocet per day.

\section{Case 2}

Velma presents for a revision of her total hip replacement. She takes $60 \mathrm{mg}$ of MS Contin bid plus two to four Tylenol \#4 per day.

\section{Case 3}

Sarah is a 47-yr-old female with a pathological fracture of her femur for $i m$ nailing. She is on $s c$ infusion of Dilaudid and is getting $10 \mathrm{mg} \cdot \mathrm{hr}^{-1}$ with good control of her pain prior to fracturing her femur.

\section{Case 4}

Tim, an iv drug user presents for debridement of his arm. He uses an unknown amount of Heroin per day, and $50 \mathrm{mg} \cdot \mathrm{day}^{-1}$ of Methadone.

\section{Case 5}

Harry is on patient-controlled analgesia (PCA) Morphine for pain from a compound fracture. Currently he is using $40-50 \mathrm{mg}$ of morphine every four hours. He presents for debridement of his leg.

\section{Case 6}

Sally presents for her sixth laparotomy due to inflammatory bowel disease. Because she previously got better relief with meperidine as opposed to morphine, she is started on PCA Demerol. On the second postoperative day she is using $400 \mathrm{mg}$ every four hours.

Patients like the above six cases represent a challenge both for intraoperative and postoperative management of their anesthesia and pain control. As time goes on, we can expect to see more, not less, of these patients.

The efficacy of narcotics in acute pain is well established. With the use of PCA, it is apparent that patients often require and can tolerate more than the traditional " $15 \mathrm{mg}$ every four hours".

Our palliative and primary care colleagues have become adept at treating the pain of malignancy. This often involves the use of what seem to be enormous doses of narcotics. Palliative patients may present to the operating room for conditions such as fractures or bowel obstructions.

The use of narcotics in chronic non-malignant pain has been accepted by the provincial colleges in both Alberta $^{1}$ and Ontario. Their use is also accepted by the Canadian and American Pain Societies. There have been a number of randomized double blind studies that have shown efficacy of oral and transcutaneous narcotics both for pain and for increased function..$^{3-6}$

Patients who abuse narcotics present to the operating room and the acute pain service and represent a challenge in management of both their pain and their addiction.

Probably no specialty outside of anesthesia is as familiar with narcotics. We use them intra-operatively and for postoperative pain control. In fact we tend to use three to four injectable narcotics in certain dose ranges. Outside of the acute pain service we don't follow our patients and even on the acute pain service (APS), only for a few days. We are unfamiliar with oral medications that are not injectable or with the oral doses of medications that we do inject. Because of this we often end up providing sub-optimum analgesia for challenging patients as above.

Most patients who are on narcotics chronically will develop tolerance to the effect of the narcotic, meaning that they will require higher doses of the agent to obtain the same effect. They will also become dependent on the narcotic, meaning that if the agent is stopped abruptly or even given in doses lower than accustomed it will result in a withdrawal syndrome.

Addiction is a more complex psycho-social condition. Most addicts are both dependent or tolerant to narcotics. Many patients whose use of narcotics is

\footnotetext{
From the Department of Anesthesiology and Pain Medicine, University of Alberta Hospitals, Edmonton, Alberta, Canada.

Address correspondence to: Dr. Brian Knight, Department of Anesthesiology and Pain Medicine, 3B2.32 Walter C. Mackenzie Health

Sciences Centre, 8440 - 112 Street, Edmonton, Alberta T6G 2B7, Canada. Phone: 780-407-8861; Fax: 780-407-3200;

E-mail: meknight@telusplanet.net
} 
legitimate have been labelled as addicts. Many addicts may have chronic pain either preceding or as a result of their addiction.

Tolerance dependence or even addiction can be developed to other drugs including barbiturates, benzodiazepines, beta-blockers, nicotine, alcohol and caffeine.

Opioids work by modulating the flow of nociceptive impulses at the spinal cord, at higher centres and peripherally. The transmission and modulation of pain at the spinal cord involves multiple neurotransmitters and neurons. Research has focused on excitatory amines including glutamate and glycine, which transmit nociceptive impulses and enhance the transmission. One class of glutamate receptor is the N-Methyl D-Aspartate (NMDA) receptor. Laboratory and clinical evidence suggest that this receptor is at least partially responsible for the development of tolerance. A number of mechanisms are postulated and there are probably multiple mechanisms at play including receptor changes and even cell death..$^{7-10}$

There are a number of oral agents which patients may be taking preop, including codeine, hydromorphone, oxycodone, meperidine and morphine. Methadone is also now being used for both chronic and cancer pain. The transdermal fentanyl patch is available in strengths of 25, 50, 75 and $100 \mu \mathrm{g} \cdot \mathrm{hr}^{-1}$. There are two issues to consider when looking at oral narcotics. The first is the relative potency of the agent. Several potency tables are in use. There is considerable inter-individual variation, however, and it is best to regard these tables as guidelines. The other is the bioavailability of oral vs parenteral formulations. Most oral medications undergo first pass metabolism. This means that a higher dose is needed to obtain the same effect as parenterally, and it is necessary to consider active or toxic metabolites such as the morphine 6- glucuronide or normeperidine, which can cause seizures. In our hospital we use the following Table on the APS. (Dr. S. Rashiq personal communication).

Often the choice of analgesic medication is the result of a trial and error process. While all exogenous narcotics act as agonists, the degree and type of interaction will differ with varying narcotics. There are multiple phenotypical types of mu receptor present in the population. ${ }^{11}$ Some drugs have effects beyond the mu receptor such as methadone's antagonist effect on the NMDA receptor ${ }^{12}$ and oxycodone's effect on the kappa receptor. ${ }^{13}$

Because of subtle differences in the drug receptor interactions, there may not be complete cross-tolerance to different drugs. Palliative care specialists make use of this to treat tolerance in patients requiring higher doses. This is unpredictable however; often the opposite occurs where a patient may get relief with a dose of one drug but not with an "equivalent" dose of another drug.

There is no maximum dose of any narcotic. The dose is limited by the presence of analgesia, or by side effects such as sedation and respiratory depression. At higher doses myoclonus or hyperalgesia may occur. At high doses of meperidine seizures can occur because of the metabolite normeperidine. The management of the narcotic tolerant patient in the perioperative period is quite simple. Give enough of the drug. In achieving this simple goal, we come up against our inexperience, our comfort levels, and our surgical, nursing and pharmacy colleagues.

There is no consensus into how to manage these patients. I will present how I would like to manage these patients, based on my experiences with acute and chronic pain patients.

With the possible exception of Tim our heroin addict, most patients have a baseline level of pain onto

TABLE

\begin{tabular}{|c|c|c|c|c|}
\hline Drug & $\begin{array}{l}\text { Parenteral dose }(\mathrm{mg}) \\
\text { equivalent to } 10 \mathrm{mg} \text { iv } \\
\text { Morphine }\end{array}$ & $\begin{array}{l}\text { Oral dose ( } \mathrm{mg} \text { ) } \\
\text { equivalent to } 30 \mathrm{mg} \\
\text { oral morphine }\end{array}$ & $\begin{array}{l}\text { Bioavailability of oral } \\
\text { dosage form }\end{array}$ & Dosing interval (hr) \\
\hline Morphine & 10 & 30 & 0.3 & 3 \\
\hline Anileridine (leritine) & 25 & 75 & 0.3 & 3 \\
\hline Codeine & 100 & 300 & 0.3 & 3 \\
\hline Diamorphine (Heroin) & 5 & 12.5 & 0.4 & 3 \\
\hline Fentanyl & 0.1 & & & 1 \\
\hline Hydromorphone (Dilaudid) & 2 & 3 & 0.6 & 3 \\
\hline Levorphanol & 2 & 4 & 0.5 & $6-12$ \\
\hline Meperidine & 80 & 250 & 0.3 & 3 \\
\hline Methadone & $2-10$ & $2-10$ & 1.0 & $8-12$ \\
\hline Oxycodone (Percocet, OxyContin) & 10 & 12 & 0.8 & 3 \\
\hline Propoxyphene (Darvon) & 50 & 100 & 0.5 & 4 \\
\hline
\end{tabular}


which acute surgical pain will be superimposed. In some cases such as our lumbar discectomy patient, it is possible that his baseline, pain may actually be better after his surgery.

\section{The preoperative period}

I usually try to find out what the patient's total daily dose of medication is. This involves asking the patient in a non-judgemental way. These patients may feel guilty or defensive over their use of analgesics. You must let the patient know that you accept that they are on this medication and you need to know how much they are taking in order to plan their anesthetic.

I usually give the patient about half their total daily dose as a sustained release preparation. A patient taking $60 \mathrm{mg}$ of oxycodone would get $30 \mathrm{mg}$ of OxyContin. If a patient's medication is not available in a long acting form, I order an "equivalent" dose of a long acting medication. Methadone with its long halflife is an attractive drug, but requires special licensing and has an unpredictable half-life, so I usually do not start it, although in patients already taking it, I try to make sure it is given preop. Fentanyl patches should be left on and it may be useful to put a fresh patch well away from the surgical site, preoperatively.

Adjuncts should also be ordered preoperatively where appropriate. Acetaminophen can be given orally in a dose of $15 \mathrm{mg} \cdot \mathrm{kg}^{-1}$ if not contraindicated. This is important in the patient using large amounts of acetaminophen preoperatively. I believe that patients can be dependent on acetaminophen and will get reduced analgesia if it is witheld, even if an equivalent amount of narcotic is given.

If not contraindicated, non-steroid anti-inflammatory drugs (NSAIDs) should also be given preoperatively. I prefer to give them by mouth. Injectable ketorolac can be given otherwise.

Acetaminophen and NSAIDs may seem to be "impotent" in the patient who is on large amounts of narcotics, but I believe they can enhance the analgesia and reduce perioperative narcotic requirements. ${ }^{14}$

Patients who are dependent on narcotics may also be dependent on a variety of other medications like tranquillizers, antidepressants, anticonvulsants, and nicotine.

Benzodiazepines and other sedative hypnotics are unfortunately widely prescribed and many narcotic tolerant patients are also on one or more of these agents. The perioperative period is NOT the time to stop these drugs; they should be ordered preoperatively and continued postoperatively. Substitution of a longer acting agent may be more appropriate.

Most of the selective serotonin uptake inhibitors and the tricyclic antidepressants are safe to give in the perioperative period. These drugs have a long half-life and a dose given preoperatively will last into the postoperative period. Physiological dependence probably does not develop to these drugs, but patients are used to their mood altering effects and the loss of these effects may prove deleterious. It is also wise to continue any antipsychotics that the patient is on.

Some patients dependent on nicotine may have considerable distress perioperatively. Transdermal nicotine preparations may reduce the patient's stress.

Alpha, agonists may be useful adjuncts. Clonidine is used in the treatment of narcotic and other drug withdrawal and has been shown to reduce perioperative narcotic requirements. Clonidine can be given in a dose of $2-4 \mu \mathrm{g} \cdot \mathrm{kg}^{-1}$. Clonidine reduces anesthetic requirements and you may need to titrate your anesthetic agents. It should be used cautiously in the hypovolemic patient. ${ }^{15}$

\section{Intraoperative management}

We are accustomed to balance anesthesia using inhaled anesthetics combined with narcotics. In the narcotic tolerant patient however our usual doses of narcotics may be ineffective.

Local and regional anesthesia are useful in the narcotic tolerant patient either alone or with a general anesthetic. However, patients still dependent on narcotics will require maintenance doses. You must also plan for when the local wears off as it could take some time to catch up with analgesia.

The dose of epidural or intrathecal narcotics can and should be increased. Epidural narcotics are about ten times as potent as iv narcotics, intrathecal narcotics are about 100 times as potent. An appropriate dose can be derived by converting the patient's total daily dose to iv morphine or hydromorphone and dividing the dose by ten for epidural or 100 for intrathecal. Our patient who takes $120 \mathrm{mg} \cdot$ day $^{-1}$ of po morphine corresponds to 60 $\mathrm{mg} \cdot$ day $^{-1}$ of $i v$ morphine, which is equivalent to $0.6 \mathrm{mg}$ intrathecally or $6 \mathrm{mg}$ epidurally.

Selecting the right dose of intraoperative narcotic is tricky in patients on higher doses. While it is appropriate to use a "maintenance" dose of narcotic, I have no way of predicting how much more narcotic a patient will require. The patient is under anesthesia and can't tell you how much he needs. My approach is to give a dose about $25 \%$ higher than normal and titrate according to heart rate and blood pressure. Another approach is the use of long and short acting narcotics, using the short acting agent as the extra narcotic. I try to get the patient breathing spontaneously at the end of the case and will titrate in more narcotics.

One method in patients who have not been given a long acting agent preoperatively, is to figure out a 
patient's hourly requirements based on their 24-hr dose and infuse an equivalent dose. This can be used in our palliative patient but can also be used in patients on large amounts of PCA. This can be supplemented by boluses or by increasing the infusion rate by $10-25 \%$.

Occasionally patients, despite apparently being tolerant, may be slow to breathe or wake up despite what you thought was the right amount of drug. This usually responds to small $\left(1-2 \mu \mathrm{g} \cdot \mathrm{kg}^{-1}\right)$ doses of naloxone or flumazemil. Analgesia is usually not reversed with lower doses of naloxone.

In the postanesthesia recovery room, nurses can titrate narcotics to effect. Larger doses may be required and it is important to reassure them.

I find ketamine to be useful perioperatively in all patients but especially in the narcotic tolerant patient. Subanesthetic doses of ketamine not only reduce pain postoperatively but may reduce pain for long periods of time. I usually give $0.5 \mathrm{mg} \cdot \mathrm{kg}^{-1}$ on induction and maintain the patient with $0.25 \mathrm{mg} \cdot \mathrm{kg}^{-1} \cdot \mathrm{hr}^{-1}$, in addition to narcotics. ${ }^{16}$ Ketamine prevents the onset of tolerance and treats tolerance and dependence once established. ${ }^{17}$ At this dose, emergence phenomena are uncommon.

\section{Postoperative pain management}

The postoperative management of the narcotic-dependent patient can be frustrating. The principle is to give enough of the medication. Patients will often use huge amounts of narcotics while complaining of poor pain control. The principle here is to ensure that they get a maintenance dose equivalent to their pre-operative dose and for increases above this. If possible, I put the patient on a long acting po agent, preferably what they used preoperatively and supplement with PCA. If it is not possible to use po drugs, I use a background infusion. Some long-acting agents can be given rectally. Fentanyl patches should have been left on.

Meperidine's metabolite, normeperidine causes seizures. In a typical size person, this may occur at about $400 \mathrm{mg}$ per four hours. The solution is to switch the patient to another narcotic, but some of these patients are on meperidine because "nothing else works" and may be resistant to other medications. I try to deal with this by using an oral dose of another narcotic adding oral clonidine.

Ketamine can be a useful additive to PCA. Various mixtures have been described. In patients on larger doses of narcotics the concentration of ketamine should be decreased to avoid giving general anesthetic doses. Reports of the efficacy of using ketamine with PCA have been conflicting but these have been studied in non-tolerant patients. ${ }^{18}$ Palliative care experience suggests that ketamine may be a useful adjunct in the narcotic tolerant patient. There have been case reports of the usefulness of ketamine in acute pain management in narcotic tolerant patients. ${ }^{19,20}$

Clonidine can be useful in the patient who is using large amounts of narcotics. Oral clonidine has been shown to reduce PCA consumption. ${ }^{21}$ Clonidine can be given orally in doses of $2-5 \mu \mathrm{g} \cdot \mathrm{kg}^{-1}$. As clonidine is an antihypertensive, you may see hypotension especially in the hypovolemic patients. This responds to fluid boluses. Injectable or transdermal preparations of clonidine are not available in Canada. Injectable dexmedetomidine may be useful.

When the use of clonidine or ketamine is considered in a narcotic tolerant patient, the goal is not to reduce narcotic consumption but to enhance analgesia. If the patient is getting good pain control with minimal side effects, there is no need to add anything, no matter what the dose.

In patients with no contraindications I order acetaminophen $4 \mathrm{~g} \cdot$ day $^{-1}$ plus a NSAID.

Epidural analgesia is an excellent form of analgesia for the narcotic tolerant patient. Local anesthetic infusions are preferable. Doses of epidural narcotics can be increased. It is important to remember that the patient will need to have a systemic dose of narcotic. This can usually be the long acting form of their usual narcotic. Again, clonidine is useful here.

Patients should get their preoperative medications such as tranquillizers, antidepressants, anticonvulsants and muscle relaxants as soon as possible postoperatively.

\section{Discharge}

Some patients may have their pain reduced as a result of surgery, but many patients can expect to require doses of narcotics similar to what they were on preoperatively. At some point, it will be necessary to discontinue the PCA or the epidural. This will involve in most cases switching the patient to an oral medication.

I usually look at the PCA consumption over the last $24-48 \mathrm{hr}$, give $1 / 2$ to $2 / 3$ of the total daily dose as a long-acting medication and the remainder as shortacting oral agent for breakthrough pain. In patients who are on large doses of PCA, I often will start them on a long acting oral agent one to two days before stopping the PCA.

\section{The addict}

Management of the true narcotic addict can be challenging. Remember that we are not going to cure their problem during this hospital admission. The surgeon may wish them to stay in hospital for wound care or other issues. It is important that they not sign themselves out early. Our principle should be one of 
harm reduction in dealing with the addicted patient, using the above principles.

Many factors, including drugs, complicate the perioperative management of these patients. Anesthesiologists have learned to deal with challenges such as sc heparin, warfarin, and mono amine oxydase inhibitors. The patient who is dependent on narcotics is just another challenge that we should be able to deal with in a capable, professional and patient centred fashion.

\section{References}

1 College of Physicians and Surgeons of Alberta. Management of chronic non-malignant pain. http://www.cpsa.ab.ca/publicationsresources/policies.asp

2 Canadian Pain Society. Use of opioid analgesics for the treatment of chronic non-cancer pain- A consensus statement and guidelines. http://www.pulsus.com/Pain/03_04/opio_ed.htm

3 Allan I, Hays H, Jensen NH, et al. Randomised crossover trial of transdermal fentanyl and sustained release oral morphine for treating chronic non-cancer pain. BMJ 2001; 12: 322: 1154-8.

4 Jadad AR, Carroll D, Glynn CJ, Moore RA, McQuay HJ. Morphine Responsiveness of Chronic Pain: double blind cross-over study with patient controlled analgesia. Lancet 1992; 339: 1367-71.

5 Moulin DE, Iezzi A, Amireh R, Sharpe WKJ, Boyd D, Merskey $H$. Randomised trial of oral morphine for chronic non cancer pain. Lancet 1996; 347: 143-7.

6 Arkinstall W, Sandler A, Goughnour B, Babul N, Harsanyi Z, Darke AC. Efficacy of controlled-release codeine in chronic non-malignant pain: a randomized, placebo-controlled clinical trial. Pain 1995; 62: 169-78.

7 Mao J, Sung B, Ji RR, Lim G. Chronic morphine induces downregulation of spinal glutamate transporters: implications in morphine tolerance and abnormal pain sensitivity. J Neurosci 2002; 22: 8312-23.

8 Mao J, Sung B, Ji RR, Lim G. Neuronal apoptosis associated with morphine tolerance: evidence for an opioidinduced neurotoxic mechanism. J Neurosci 2002; 22: 7650-61.

9 Gardell LR, Wang R, Burgess SE, et al. Sustained morphine exposure induces a spinal dynorphin-dependent enhancement of excitatory transmitter release from primary afferent fibers. J Neurosci 2002; 22: 6747-55.

10 Mao J, Mayer DJ. Spinal cord neuroplasticity following repeated opioid exposure and its relation to pathological pain. Ann N Y Acad Sci 2001; 933: 175-84.

11 Lee NM, Smith AP. Opioid receptor polymorphism and opioid abuse, Pharmacogenomics 2002; 3: 219-27.

12 Hewitt D. The use of NMDA-receptor antagonists in the treatment of chronic pain. Clin J Pain 2000; 16(2 Suppl): S73-9.

13 Ross FB, Smith MT. The intrinsic antinociceptive effects of oxycodone appear to be kappa-opioid receptor mediated. Pain 1997; 3: 151-7.

14 Hyllested M, Jones S, Pedersen JL, Keblet $H$. Comparative effect of paracetamol, NSAIDs or their combination in post operative pain management: a qualitative review.

15 Khan ZP, Ferguson CN, Jones RM. Alpha 2 and inidazoline receptor agonists. Their pharmacology and therapeutic role. Anaesthesia 1999; 54: 146-65.

16 De Kock M, Lavand'homme P, Waterloos H. Balanced analgesia' in the perioperative period: is there a place for ketamine? Pain 2001; 92: 373-80.

17 Gonzalez P, Cabello P, Germany A, Norris B, Contreras $E$. Decrease of tolerance to, and physical dependence on morphine by, glutamate receptor antagonists. Eur J Pharmacol 1997; 332: 257-62.

18 Murdoch CJ, Crooks BA, Miller CD. Effect of the addition of ketamine to morphine in patient-controlled analgesia. Anaesthesia 2002; 57: 484-8.

19 Mercadante S, Arcuri E, Tirelli W, Casuccio A. Analgesic effect of intravenous ketamine in cancer patients on morphine therapy: a randomized, controlled, double-blind, crossover, double-dose study. Pain Symptom Manage 2000; 20: 246-52.

20 Haller G, Waeber JL, Infante NK, Clergue F. Ketamine combined with morphine for the management of pain in an opioid addict. Anesthesiology 2002; 96: 1265-6.

21 Park J, Forrest J, Kolesar R, Bhola D, Beattie S, Chu C. Oral clonidine reduces postoperative PCA morphine requirements. Can J Anaesth 1996; 43: 900-6. 